\title{
ВMJ Global Health Youth lost to homicides: disparities in survival in Latin America and the Caribbean
}

\author{
Vladimir Canudas-Romo, ${ }^{\oplus 1}$ José Manuel Aburto ${ }^{\circledR 2,3}$
}

To cite: Canudas-Romo V, Aburto JM. Youth lost to homicides: disparities in survival in Latin America and the Caribbean. BMJ Glob Health 2019;4:e001275. doi:10.1136/ bmjgh-2018-001275

Handling editor Seye Abimbola

- Additional material is published online only. To view please visit the journal online (http://dx.doi.org/10.1136/ bmjgh-2018-001275).

VC-R and JMA contributed equally.

Received 2 November 2018 Revised 23 January 2019 Accepted 25 January 2019

Check for updates

(c) Author(s) (or their employer(s)) 2019. Re-use permitted under CC BY-NC. No commercial re-use. See rights and permissions. Published by BMJ.

${ }^{1}$ School of Demography, College of Arts and Social Sciences, Australian National University, Canberra, Australian Capital Territory, Australia

${ }^{2}$ Interdisciplinary Centre on Population Dynamics (CPop), University of Southern Denmark, Odense, Denmark

${ }^{3}$ Max Planck Institute for Demographic Research, Rostock, Germany

\section{Correspondence to} Dr Vladimir Canudas-Romo; vladimir.canudas-romo@anu. edu.au and Dr José Manuel Aburto; jmaburto@sdu.dk

\section{ABSTRACT}

Introduction The homicide rates among young men in Latin America and the Caribbean (LAC) are the highest in the world. It is not clear how this has impacted the life expectancy in these countries. This research has two purposes: (1) to quantify the impact of homicides on the mortality gap between LAC and high-income countries over recent years and (2) to assess the changes in homicide impact in overall survival over time.

Methods Causes of death data were extracted for 23 countries in the LAC and 15 European countries (average European union-15 [EU-15]), using UN, UNODC, WHO, HMD and IHME databases for the period 2005-2014. The contribution by homicide deaths to the change in life expectancy, over time and as a difference between two populations, was quantified using decomposition methods. Results The contribution by homicide mortality to changes in life expectancy levels differed widely across the examined LAC countries. In Honduras, homicide mortality accounted for $1.75(95 \% \mathrm{Cl} 1.64$ to 1.86$)$ and $6.30(95 \% \mathrm{Cl}$ 6.07 to 6.53 ) years lower life expectancy than in the EU-15 countries for women and men, respectively. Contrary to this, homicide was just accountable for less than a couple of months of life expectancy differences between Chile and EU-15. Jamaica had the largest reduction in homicides and its impact increased life expectancy over time by almost half a year for men. However, Mexican men and Honduran women have experienced increases in mortality by homicide, which decreased their life expectancy by more than a quarter of a year between 2005 and 2014.

Conclusions Excess mortality related to homicides in young people accounted for major changes in life expectancy in the LAC region. Furthermore, reducing excess mortality due to homicides is a crucial goal to further increase longevity towards levels of low-mortality countries. These reductions might prevent homicides spreading to other parts of Latin America. Decision and policy-makers in LAC need to address this immediately, and investing in the young population needs to be given a high priority.

\section{INTRODUCTION}

Over two million young people aged 15-29 died in Latin America and the Caribbean (LAC) between 2005 and 2015 (estimates vary from $2182832^{1}$ to $2230872^{2}$ ). Young

\section{Key questions}

What is already known?

- Homicide rates, which have declined in other parts of the world, are rising in Latin America and the Caribbean (LAC) region, and most victims are adolescents and young adults.

- Time-trend analysis has documented how rapidly violence can escalate in a country, while reductions take place slowly.

What are the new findings?

- Great diversity in terms of survival and risk of mortality by homicide has evolved among LAC countries, in recent years, with comparable impact on reducing and increasing life expectancy in different countries.

- For the middle and low life expectancy countries, homicide mortality, particularly among young men, is a major explanatory factor of the gap in life expectancy with respect to high-income countries.

- The forerunners of longevity in the region have the lowest burden of homicide mortality.

What do the new findings imply?

- Efforts are needed to bring the region together to reduce the high levels of homicide mortality and to prevent a spread to other parts of LAC.

men account for most of those deaths, and their homicides correspond to $27 \%{ }^{3}-28 \%^{1}$ of the overall mortality in those ages. Furthermore, close to half of all homicides occur in the age group $15-29\left(45 \%^{1}-51 \%^{3}\right)$. However, homicide rates differ across the LAC region. The two most populated countries, Brazil and Mexico, account for the highest number of homicides in absolute numbers. In relative terms, the LAC region has been ranked as the most dangerous in the world ${ }^{4}$; in El Salvador and Honduras in 2015 a staggering rate of 109 and 64 homicides per 100000 persons, respectively, has been reported for men while in the same year 27 and 57 homicides per 100 000 persons have been noted in Colombia and Venezuela, respectively. ${ }^{5}$ In contrast, Argentina and Peru only list 7 homicides per 100 
000 persons while in Chile and Cuba 4 and 5.2 homicides per 100000 persons, respectively, were reported which were comparable to the rate of 5 per 100000 persons listed for the USA in $2015 .^{5}$

Differences in mortality between LAC countries have not only been noted with respect to homicides. ${ }^{6}$ South American countries, such as Argentina, Chile and Uruguay, underwent a smooth epidemiological transition from reductions in rates of infectious diseases towards declines in cardiovascular deaths. ${ }^{7}$ However, Central American countries, such as Mexico, Guatemala and Honduras, as well as Brazil and Paraguay in South America, experienced a rapid epidemiological transition combining cardiovascular and infectious diseases since the 1980s. ${ }^{8}$ In addition, many of these countries are also burdened with high rates of homicides (online supplementary figures $\mathrm{Aa}$ and $\mathrm{Ab}$ depicting the homicide rates and counts for women and men in the region, respectively, and online supplementary figure A showing a map of homicides in the region are found in the online supplementary appendix).

In high-income countries, the second half of the 20th century was marked first by a slow mortality reduction, and since 1970 s, more rapid mortality reductions, particularly due to better treatment options for cardiovascular diseases. ${ }^{9}$ During the same period, even more pronounced mortality improvements were experienced in several LAC countries, leading to closing the mortality gap with high-income countries. ${ }^{10}$ However, the remaining disparity in mortality between LAC and high-income countries might be challenged by the ageing of the population. ${ }^{11}$ Furthermore, it is unclear whether the homicide burden has counteracted the closing of the mortality gap.

Given the remarkably high rates of homicides and inequality in health outcomes in LAC, this research has two purposes: (1) to quantify the impact of homicides on the mortality gap between LAC and high-income countries over recent years and (2) to assess the changes in homicide impact in overall survival over time. By analysing life expectancy levels over time and using a representative European region as comparison, we are able to determine the relevance of this health challenge in shaping improvements in longevity in the region. The European comparison group is diverse, as is the LAC region, and has one of the lowest levels of homicide mortality (0.98 homicides per 100000 people $),{ }^{5}$ justifying its use as a benchmark. On a wider public health context, our results shed light on whether the effects of the high levels of violence in LAC, have a lasting impact on the overall mortality and to assess if interventions are needed.

\section{METHODS}

Analysing data on homicide and other causes of death as well as drawing comparisons across time and countries is one of the top priorities in public health prevention. ${ }^{12}$
To study the diversity in survival and the epidemiology of LAC, age-specific and cause-specific decompositions of differences in life expectancy over time were carried out. The time of analysis was: 1990-2014 for life expectancy trends, 2010-2014 for the comparisons of each LAC country with a group of European countries, denoted European union-15 (EU-15), and the period from 20052009 to 2010-2014 for changes in life expectancy over time. Preliminary work on a wider range of years and number of causes of death determined the basis for the current study. ${ }^{13}$

For this analysis, countries with a population from LAC of less than 1 million in 2010 and from EU-15 of less than half a million were omitted to avoid substantial random fluctuation due to small numbers. Based on population size and available mortality data from LAC, a total of 23 countries were selected: 6 countries in the Caribbean (Cuba, Dominican Republic, Haiti, Jamaica, Puerto Rico and Trinidad and Tobago), 7 countries in Central America (Costa Rica, El Salvador, Guatemala, Honduras, Mexico, Nicaragua and Panama) and 10 countries in South America (Argentina, Bolivia, Brazil, Chile, Colombia, Ecuador, Paraguay, Peru, Uruguay and Venezuela). Table 1 lists the population sizes, life expectancy and CIs, and average yearly homicides.

\section{Sources of data}

This study involved secondary data analysis of public sources, which did not involve patients nor public (PPI). Two types of data were required to decompose the effects of different diseases on life expectancy changes: cause-specific mortality and life table data. A life table summarises the mortality experience of a population, calculating life expectancies from death rates.

Data on causes of death were obtained from World Health Organization mortality database $(\mathrm{WHO})^{3}$ and the Institute of Health Metrics and Evaluations (IHME), which contain data on cause-specific deaths over time for all the selected countries, except Haiti and Bolivia which are missing in WHO. The IHME includes rigorous assessment and estimates of the cause-of-death information provided by WHO and the United Nations Office on Drugs and Crime (UNODC). ${ }^{5}$ In order to increase observations and ensure comparability across countries, we studied two periods: 2005-2009 and 2010-2014. For each LAC country, available data for the two periods were used to represent the years. For example, when using WHO data for Honduras, data were only available for the years 2008-2009 in the first period, and 2010-2013 in the second (see online supplementary appendix table A1). There are two main reasons for the shorter time frame on the causes of death analysis as opposed to the 1990-2014 for life expectancy trends: (1) Although we wanted to have an overall perspective of the trends in life expectancy, we wanted to emphasise the recent years of information on homicide mortality which in some countries in the region has increased disproportionally, (2) Causes of death information are more accurate in recent 
Table 1 Population, life expectancy and homicides in Latin America and the Caribbean

\begin{tabular}{|c|c|c|c|c|c|}
\hline \multirow[b]{2}{*}{ Region and country } & \multirow{2}{*}{$\begin{array}{l}\text { Population* }^{*} \\
2010\end{array}$} & \multicolumn{2}{|c|}{ Life expectancy 2010-2014 } & \multicolumn{2}{|c|}{ Homicides $†$} \\
\hline & & Females & Males & UNODC & IHME \\
\hline Latin America and the Caribbean & 599823 & $77.9(77.5,78.2)$ & $71.2(70.7,71.6)$ & 123688 & 129438 \\
\hline Caribbean (six countries) & 41621 & & & & \\
\hline Cuba & 11308 & $81.3(80.9,81.5)$ & $77.1(76.7,77.4)$ & 519 & 622 \\
\hline Dominican Republic & 9898 & $76.5(76.0,76.8)$ & $70.2(69.7,70.6)$ & 1859 & 1300 \\
\hline Haiti & 10000 & $64.4(63.8,64.8)$ & $60.2(59.6,60.6)$ & 874 & 755 \\
\hline Jamaica & 2741 & $77.9(77.4,78.2)$ & $73.1(72.6,73.4)$ & 939 & 638 \\
\hline Puerto Rico & 3710 & $83.2(82.8,83.4)$ & $75.2(74.8,75.5)$ & 879 & 666 \\
\hline Trinidad and Tobago & 1328 & $73.8(73.4,74.1)$ & $66.9(66.4,67.2)$ & 403 & 285 \\
\hline Central America (seven countries) & 161117 & & & & \\
\hline Costa Rica & 4545 & $81.7(81.3,81.9)$ & $76.7(76.3,77.0)$ & 459 & 332 \\
\hline El Salvador & 6038 & $77.1(76.6,77.4)$ & $67.9(67.4,68.3)$ & 3477 & 3180 \\
\hline Guatemala & 14732 & $75.0(74.5,75.4)$ & $67.9(67.4,68.4)$ & 4336 & 5334 \\
\hline Honduras & 7504 & $75.4(74.9,75.8)$ & $70.4(69.9,70.8)$ & 6575 & 2712 \\
\hline Mexico & 118618 & $78.9(78.5,79.2)$ & $74.0(73.6,74.4)$ & 20800 & 19983 \\
\hline Nicaragua & 5738 & $77.5(77.0,77.8)$ & $71.4(70.9,71.7)$ & 732 & 590 \\
\hline Panama & 3621 & $80.5(80.1,80.8)$ & $74.3(73.8,74.7)$ & 680 & 576 \\
\hline South America (10 countries) & 397085 & & & & \\
\hline Argentina & 41223 & $79.8(79.4,80.1)$ & $72.2(71.7,72.4)$ & 3227 & 2558 \\
\hline Bolivia (Plurinational State of) & 9918 & $70.2(69.6,70.6)$ & $65.3(64.7,65.8)$ & 736 & 639 \\
\hline Brazil & 198614 & $77.9(77.4,78.1)$ & $70.3(69.8,70.6)$ & 51132 & 56530 \\
\hline Chile & 17015 & $84.1(83.7,84.4)$ & $78.1(77.7,78.4)$ & 561 & 836 \\
\hline Colombia & 45918 & $77.4(77.0,77.7)$ & $70.2(69.7,70.6)$ & 12209 & 16872 \\
\hline Ecuador & 14935 & $78.4(77.9,78.7)$ & $72.8(72.3,73.2)$ & 1988 & 2174 \\
\hline Paraguay & 6210 & $74.9(74.5,75.3)$ & $70.7(70.2,71.1)$ & 645 & 935 \\
\hline Peru & 29374 & $76.8(76.4,77.2)$ & $71.5(71.1,71.9)$ & 2074 & 1046 \\
\hline Uruguay & 3374 & $80.4(80.0,80.7)$ & $73.2(72.8,73.5)$ & 239 & 161 \\
\hline Venezuela (Bolivarian Republic of) & 28996 & $78.2(77.8,78.5)$ & $69.9(69.5,70.3)$ & 8345 & 10714 \\
\hline
\end{tabular}

IHME data were available for every single year.

${ }^{*}$ Population counts in thousand from UN database.

†Annual average homicides 2010-2014.

IHME, Institute of Health Metrics and Evaluations; UN, United Nations; UNODC, United Nations Office on Drugs and Crime;

years, and available for a larger number of countries. Additionally, the recent shorter period for the causes of death did not require dealing with changes in the International Classification of Diseases (ICD) codes, from revisions 9 th to 10 th, which on previous analysis showed some ruptures in causes of death time trends, although it was not so much the case for homicides. ${ }^{13}$ Age-specific cause-of-death data from WHO and IHME was divided with respect to homicides and all other causes of death in order to obtain their percentage composition at each age (see details in online supplementary appendix 2 ). All LAC countries reported cause-of-death data using the ICD revision 10 codes, during the study period. Cause-ofdeath information was obtained for ages $0,1-4$ and then in 5-year age groups until the last age group which had an open end although varied by country ( 80 and more, or $80+, 85+$ or $95+)$. Given that the major share of the age contribution to changes in life expectancy in LAC still occurs at ages below 80 , this was not perceived as an obstacle. Furthermore, homicides tend to concentrate in the young adult ages around $15-29$ years. Therefore, the analysis was focused on causes of death before age 80 . Following the 10th revision of the ICD, homicides were defined as deaths recorded with codes X85-Y09 or Y87.1. In addition, figures for the overall number of deaths were retrieved.

A third data source on homicide deaths was obtained from the UNODC. ${ }^{5}$ This source includes aggregate figures for the annual number of homicides by age and sex for each country, which are estimated after harmonising the definitions of homicide across countries, thus making it a good source for international comparison. 
The homicide counts from UNODC were analysed by sex using the proportions obtained from UNODC, and by age using WHO data (see details in online supplementary appendix 2).

To maximise comparability in the age and cause-ofdeath decomposition, we used life tables from the UN demographic yearbooks. ${ }^{14}$ Five-year life tables from 1990 to 1994,1995 to 1999,2000 to 2004,2005 to 2009 and 2010 to 2014 were included in order to avoid random fluctuations from year to year. UN (United Nations) life tables are centred on the middle of the year, for example, 2010-2015 corresponds to mid-2010 to mid-2015. To ensure consistency with the cause-of-death data, we considered them as corresponding to 2010-2014. These 5-year data helped to have a broad comparability across the region, since many LAC countries could be included, particularly those with only a few years' information. Finally, our interest is in the most recent years and thus the focus in the latest decade with available data. Causes of death were also organised in these five calendar years. We were able to match life table and cause-of-death data for the same years for most countries (see online supplementary appendix table A1). Table 1 also shows the disparities between the homicide data from UNODC and IHME. For Honduras, UNODC recorded three times more homicides than the IHME, and twice that number in Peru. While for Paraguay and Chile, IHME reports more homicides. On top of these discrepancies, many homicide deaths in the region go undercounted and these databases correspond to an underestimate of the actual levels of violent mortality. The analysis was carried out with both sets of data and their results included in the text and online supplementary appendix. The overall message of our study-the urgent need to put the health of the young generations at a high priority, and the regional great diversity on the risk of homicide mortality-remained irrespective of the data used.

UN life table data were compared with those of other data sources, such as the Economic Commission for $\mathrm{LAC}^{15}$, CEPAL for 2004 and $2010^{15}$; the life table collections from the Latin America Mortality Database ${ }^{16}$ and the life tables provided by each of the national statistical offices. ${ }^{17}$ The divergences between data sources varied by country. For example, coherent life expectancy time trends across the different data sources were noted for Honduras. In contrast, data from CEPAL and the UN show an overall increase in Mexican life expectancy during the first decade of the new millennium, 2000-2010, while research ${ }^{18} 19$ and the national statistical office $^{20}$ have noted a stagnation, particularly for men. This illustrates the need for caution when analysing data from this region. To account for this uncertainty, 95\% empirical CIs for life expectancy were calculated using bootstrapping with exponential distribution with piecewise constant rate ${ }^{21}$ and are presented in table 1 and in the online supplementary appendix tables A1 and A2. The latter tables correspond to the use of UNODC and WHO databases in table A1 and the IHME database in table A2, figures in the result section present the numbers of online supplementary table A1.

In order to have a reference pool of high-income countries, average life tables and cause-of-death data were calculated for a representative EU-15 comprising: Austria, Belgium, Denmark, Finland, France, Germany, Greece, Ireland, Italy, Luxembourg, The Netherlands, Portugal, Spain, Sweden and the UK. Data regarding the EU-15 countries derived from the Human Mortality Database life tables, with comparable values to the UN information, and for the causes of death from WHO databases. $^{31422}$ The average life expectancy in 2010-2014 was 83.5 years (95\% CI 83.2 to 83.7 ) for women and 78.6 years (95\% CI 78.2 to 78.8 ) for men. Online supplementary figure $\mathrm{A} 1$ in the appendix includes time trends in the EU-15 life expectancies and details of the averaging procedure to obtain the EU-15 values are found in online supplementary appendix 1 .

\section{Analysis}

Age and cause decomposition of the difference in life expectancy between each LAC country and EU-15 in 2010-2014 was performed using standard demographic techniques. ${ }^{23} 24$ This methodology helped to determine the impact of homicides on the mortality gap between LAC and the benchmark, namely the EU-15 countries with the lowest levels of homicide mortality. For example, this approach allows us to study the contribution of homicide mortality to the difference in life expectancy for men between Venezuela 69.9 years (95\% CI 69.5 to 70.3 ) and EU-15 78.6 years (95\% CI 78.2 to 78.8 ) in 2010-2014. To further assess the diversity in the region, decompositions of changes in life expectancy from 2005-2009 to 2010-2014 were constructed.

All calculations were performed using the R-software programming language. ${ }^{25}$ Details of the methodology used are found in online supplementary appendix 2 and a flow chart of the project in online supplementary appendix 3 .

\section{Role of the funding source}

The funder of the study had no role in study design, data collection, data analysis, data interpretation or writing of the report. The corresponding author had full access to all the data in the study and had final responsibility for the decision to submit for publication.

\section{RESULTS}

As seen in figure 1, life expectancy for women and men improved from 1990 to 2014 in the 23 examined countries. Based on ranking life expectancies for women in 2010-2014, countries were classified into four groups: (1) high life expectancy (less than 4 years from the highest life expectancy [HLE]), (2) medium-high life expectancy (more than four and less than 6 years from HLE), (3) medium-low life expectancy (more than 6 and less than 8 years from HLE) and (4) low life expectancy (more than 8 years from HLE). 


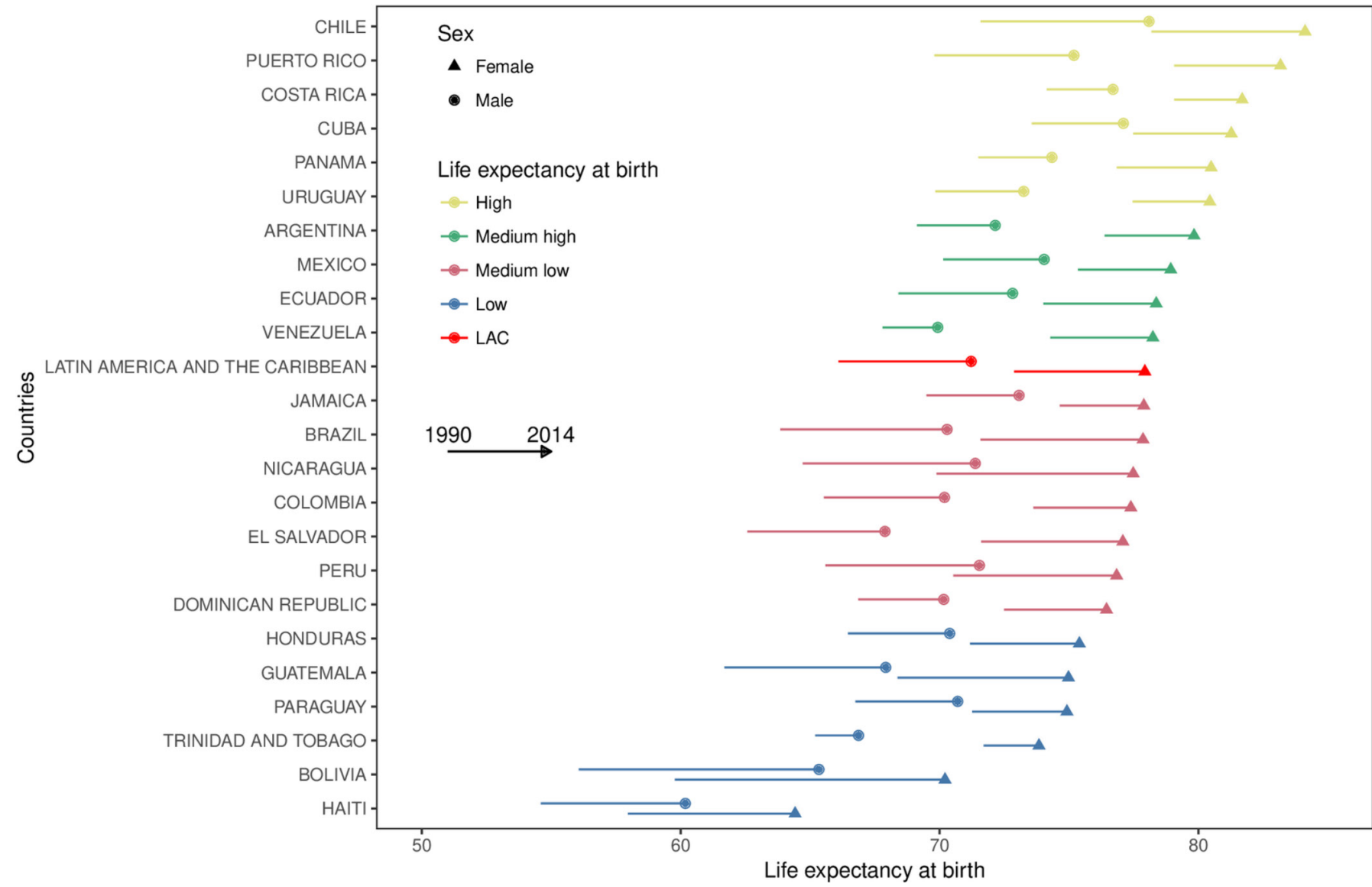

Figure 1 Life expectancy in Latin America and the Caribbean (LAC) countries from 1990 to 2014 by sex and level of life expectancy.

Figure 1 shows that all countries have experienced reductions in mortality and increases in life expectancy in the period from 1990 to 2014 . However, there are several dimensions of disparity in life expectancies: (1) a gap ranging from the HLE in 2010-2014 attained by women in Chile ( 84.1 years (95\% CI 83.7 to 84.4$)$ ) to the other extreme in Haiti lagging by more than 19 years (64.4 years (95\% CI 63.8 to 64.8 ); (2) a gap between women and men in a country; here, Haiti had the lowest gap of 3-4 years, while a difference of more than 9 years was noted for El Salvador and (3) the pace of progress in life expectancy increase, for instance, Bolivia advanced by 11.9 and 10.6 years for women and men, respectively, while the life expectancy of women from Trinidad and Tobago only increased with 2.6 years and men with 1.5 years during the 25 years of observation.

Figure 2 summarises the contribution by homicide to the life expectancy gap between LAC and EU-15 for the years 2010-2014, by life expectancy group. Each point in figure 2 is found at the crossing of life expectancy in the LAC country (horizontal axis) with the homicide contribution to that country's disadvantage respect to life expectancy in EU-15 (vertical axis). Major disparities were noted, particularly for men. An extreme was noted in Honduras where homicide mortality accounted for 6.3 years (6.1-6.5) of lagged life expectancy for men and close to 2 years for women, which was higher than for other men populations in the region. Apart from the outlier of Honduran women, high values were also found for women from Dominican Republic, El Salvador, Guatemala and Jamaica, however, all just below half a year. Even men from Argentina, Chile, Cuba and Uruguay were noted for smaller contributions by homicide to the mortality gap. Although a gradient of disparity between EU-15 and LAC countries was found with greater gap when the life expectancy was low in the LAC, this was not a straight relation. While men from Honduras, Colombia and Paraguay had similarly low life expectancies of 70 years, Honduran men experienced a contribution by homicide twice as high when compared with Colombian men, and the latter had a double as high contribution when compared with peers in Paraguay. Online supplementary tables A1 and $\mathrm{A} 2$, and figure A2 in the appendix include the overall life expectancy differences LAC versus EU-15, and all the trends found in the four life expectancy groups in figure 2 together.

During the period 2010-2014, homicides on average accounted for $17 \%$ of the life expectancy gap between LAC and EU-15, and over 32\% of the difference for El Salvador, Honduras and Colombia. Furthermore, when restricting the analysis to the age group 15-29 years, in practically all countries staggering levels were observed; for example, $90 \%$ of the gap with high-income countries 


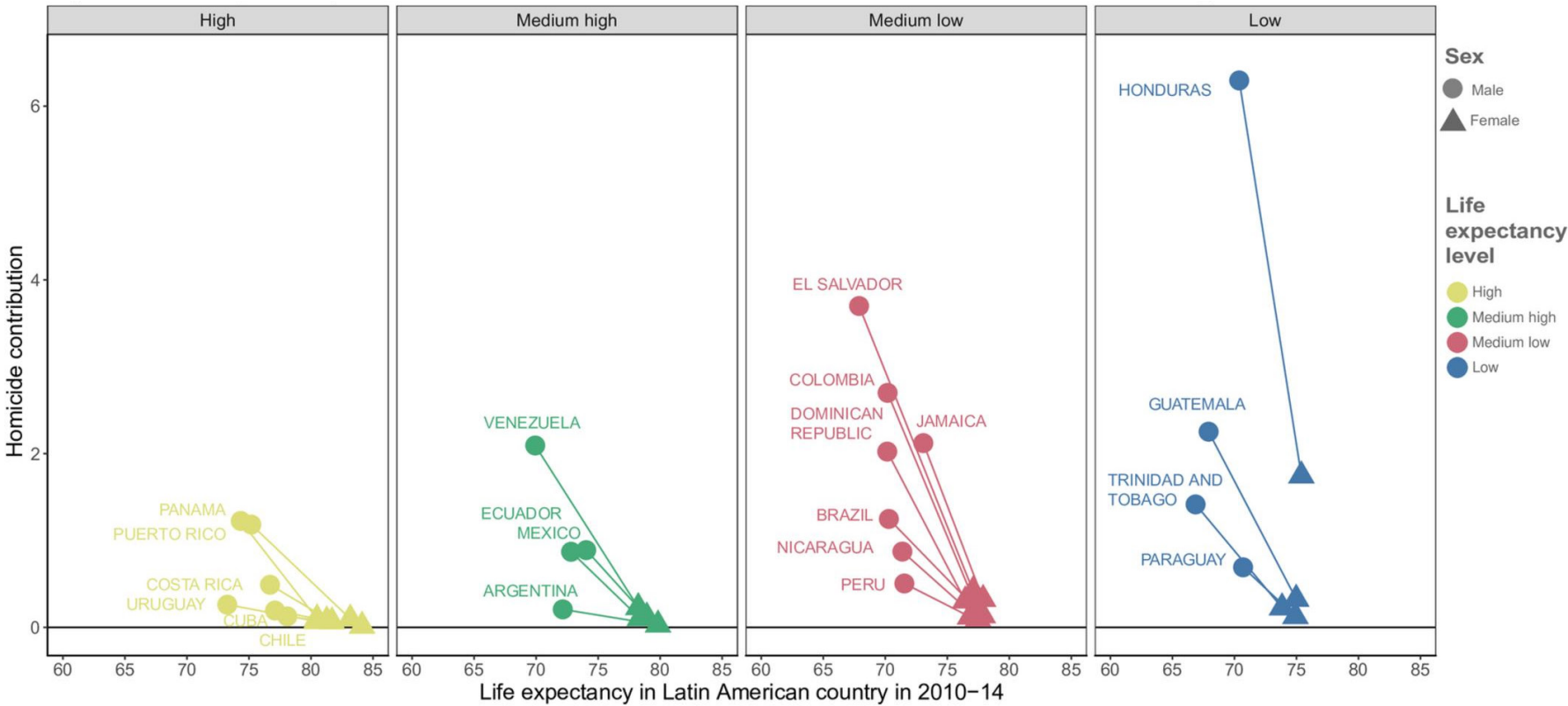

Figure 2 Homicide contribution to the gap in life expectancy between Latin America and the Caribbean countries and European union-15 for women and men, by life expectancy, 2010-2014.

was attributable to homicides in Puerto Rico, even when this country had one of the HLEs in the region. ${ }^{13}$

Figure 3 illustrates the homicide contribution to the change in life expectancy over time for LAC countries from 2005-2009 to 2010-2014, by life expectancy group. Positive values correspond to reductions in homicide mortality which translate into increased life expectancy. Negative values imply that homicides are preventing an increase in life expectancy. Across the region, the trend in the contribution by homicide differs between countries. The greatest changes in life expectancy for men affected by homicide mortality were observed in Jamaica and Paraguay where over 0.4 years were gained, while Mexico lost more than -0.3 years $(-0.4$ to -0.3$)$. Life expectancy for men increased by 1 year in Colombia, 1.5 years in Brazil and 0.7 years in Mexico from 2005-2009 to 2010-2014. Although still at a high level, the decline in homicide mortality in Colombia accounted for $22 \%$ of the increase in life expectancy. Even the stagnating homicide rates in Brazil accounted for a $4 \%$ increase in life expectancy. In Mexico, life expectancy could have increased by $46 \%$ (from 0.7 to 1.02 years) if not for a growing homicide mortality that challenged its rise. Honduras, Puerto Rico and Panama experienced large

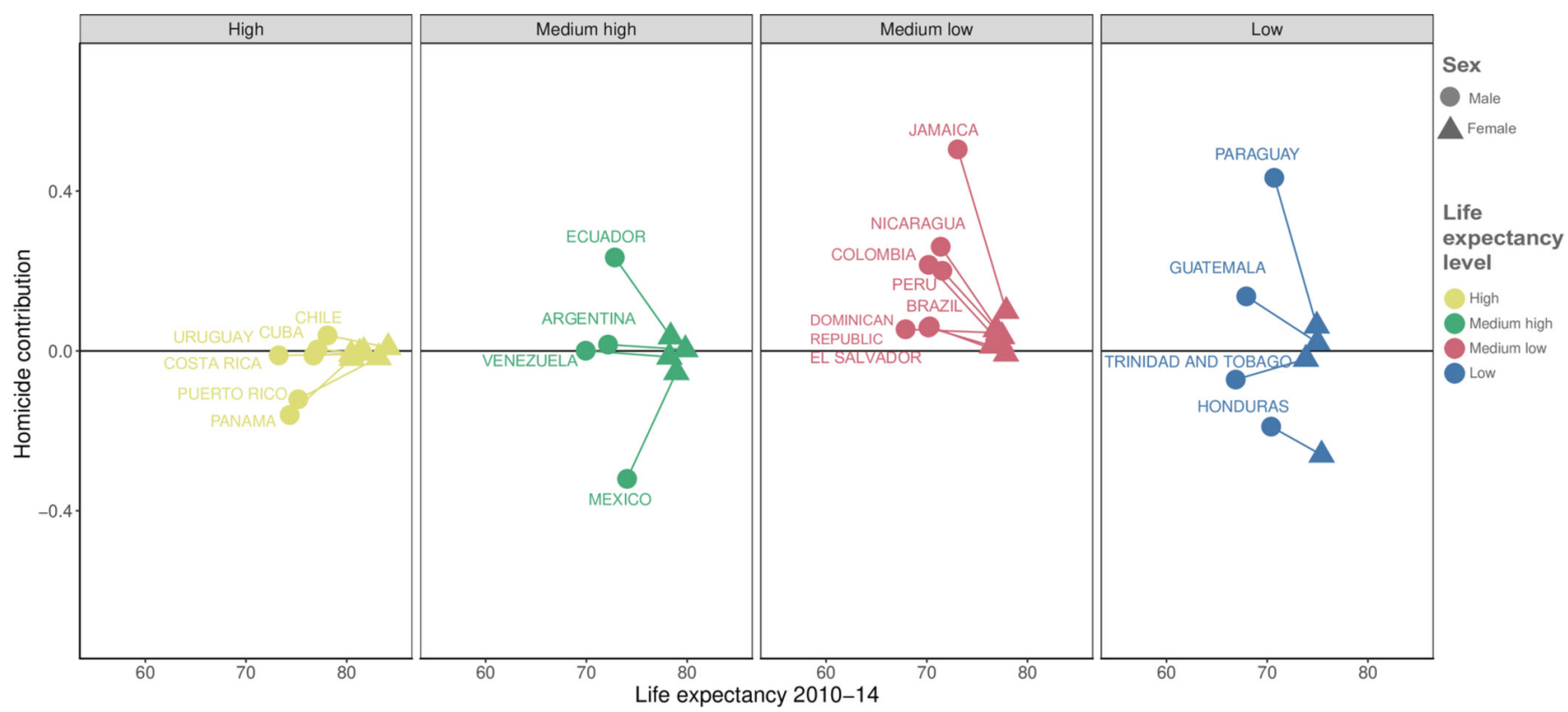

Figure 3 Latin America and the Caribbean homicide contribution to the change in life expectancy between 2005-2009 and 2010-2014 for women and men, by life expectancy, 2010-2014. 
increases in homicide rates, which opposed gains in life expectancy. Except for Honduras, the change in the contribution by homicide was greater among men than women. Online supplementary figure A3 in the appendix includes all the trends found in the four life expectancy groups in figure 3 together.

\section{DISCUSSION}

All LAC countries experienced reductions in mortality and increases in life expectancy from 1990 to 2014. Some of the best performers in terms of increases in life expectancy were poor performers in terms of economic growth, for example, Bolivia, El Salvador, Honduras and Nicaragua. ${ }^{26}$ However, while the forerunners of longevity in the region presented levels comparable to those of high-income countries, the countries lagging behind are still challenged by communicable diseases. While previous research has highlighted the disparities in life expectancies between LAC and developed countries, little attention has been diverted to homicide and its impact on overall longevity. ${ }^{137}$ Our results highlight that homicide mortality, particularly among young men, is a major explanatory factor of the gap in life expectancy in several LAC countries with respect to high-income countries. In fact, homicide rates in the region are much higher than suicide rates, in contrast to the rest of the world. ${ }^{6}$ The life expectancy forerunners of longevity are also the group of countries with the lowest burden of homicide mortality. Thus, the ranking of life expectancy into groups reflects the country-specific health challenges, and particularly the homicide burden. ${ }^{46}$

Excess homicide mortality among young people is one of the key components of changes in life expectancy in many LAC countries and in the gap with high-income countries. Excess mortality can have transcendental consequences in a population. Take, for instance, the demographic dividend or the increase in the proportion of the population that is of working age (between 15 and 64 years), which has been shaped through a transition from high to low rates of mortality and fertility. This dividend represents a window of opportunity to boost a country's development, and population policies are needed to integrate the surplus work force. ${ }^{28}$ However, the potential of the demographic dividend is jeopardised by the high numbers of young deaths. ${ }^{429}$ Crime has a perverse direct and indirect effect on economic efficiency. It directly affects the productivity of those deceased, incapacitated and incarcerated, but crime also generates social inefficiencies by reducing investment. Moreover, crime and violence are identified as the second most important public policy issues in the LAC region. ${ }^{30}$ Furthermore, educational levels strongly impact mortality levels, and coincide with the classification of life expectancy mentioned in figure 1; LAC countries with high life expectancy on average present a $96 \%$ adult literacy rate among persons 15 years and older, while the low life expectancy groups present a literacy rate of $82 \% .{ }^{31}$ Thus, enhancing the quantity and quality of educational levels would seem a promising strategy to strengthen the positive trends in the overall mortality decline and potentially result in a prevention strategy against the corroding levels of violence and homicide mortality. Previous work has emphasised school-based efforts, programme involving hope and connectedness, continuing education and training, programme aimed at reducing alcohol-related violence, as promising strategies. ${ }^{32}$

Identifying the specific historical reasons and other determinants (eg, inequality) for the current levels of homicide mortality for each LAC country is a major endeavour and beyond the scope of the current study. In addition, the pathways that lead an individual to commit a homicide or crime are multiple and complex. ${ }^{33}$ However, it is important to highlight those countries that are particularly affected by this mortality. For example, homicides in Colombia, even though still at high levels, have not increased in the last decade. Approaches such as community programme to prevent violence that focus on lessening risk factors (eg, alcohol use and firearm possession), and epidemiological surveillance has strengthen policies to reduce violence. ${ }^{34}$

In Honduras, Mano Dura (iron fist) and the anti-Maras and anti-Gangs laws aimed at reducing social violence and reinstating public security by incarcerating members of gangs demonstrated poor results. ${ }^{35}$ Not only did they fail to reduce crime and delinquency, but also they were unable to control or disband the gangs. Gang members that were easily identifiable by their tattoos, dress code and other elements, adapted rapidly hiding those elements from public and police forces. Honduran gang members were then able to go beyond the usual territorial/neighbourhood borders. At the same time prisons became centres of strong proliferation of gangs. ${ }^{35}$ Although Honduras did not experience an internal armed conflict as did neighbouring Central American countries, violence affecting men and women prevails. Furthermore, the latter suffer more extreme forms of brutality in the form of feminicide and gender violence. Honduras endorses regional and international laws against violence, for example, criminalising intrafamily violence, rape and killings of women. However, these laws are weakly implemented or even omitted. ${ }^{36}$ Violence against women has intensified in Honduras caused by the deteriorating rule of law, escalating repression, and amplified gender-based violence targeting women. Conversely, other Central American countries, such as El Salvador and Guatemala, which also exhibit high levels of violence, have made relatively more progress than Honduras towards creating specialised services for women (eg, Ciudad Mujer in El Salvador and specialised feminicide courts in Guatemala). Similarly, Nicaragua and Costa Rica have relatively lower overall levels of violence and lower levels of feminicide. ${ }^{36}$

The limitations of the study should be acknowledged. Data quality and availability of information impeded the accuracy of determining the actual damage to societies that homicide is causing. The region has experienced 
the reappearance of mass graves, and many missing individuals are not identified as homicides, generating misreporting and under-registration. ${ }^{4}$ As mentioned earlier, caution is needed when analysing records from this region. For example, different data sources showed diverse trends in life expectancy as well as in causes of death for some countries (see table 1). Although this represents a limitation of the study, our main conclusions concerning the devastating impact of homicide mortality did not differ irrespective of the data used (see online supplementary tables A1 and A2 in the appendix). ${ }^{13}$ Nevertheless, our results should be taken as an underestimate of the eroding effect of homicide in the young population of the LAC region. Thus, improving the ability of registers to collect homicide and violence related conditions using the relevant ICD codes is one of the priorities in the region. ${ }^{37}$

Region-wide efforts are needed to bring the countries together to fight the high levels of homicide mortality, and to prevent its spreading to other parts of Latin America. Over recent decades, a unique south-south knowledge exchange in public health has taken place. ${ }^{38}$ For example, the effective exchange of knowledge and experiences on conditional cash transfer schemes in the region helped improved general levels of health and increased use of health services among poor subpopulations. ${ }^{39}$ Similarly, today inter-regional exchange of strategies and actions, as well as partnerships, ${ }^{40} 41$ could help to generate the desired reductions in homicide mortality.

Homicide rates, which have declined in other parts of the world, are rising in Latin America, and most victims are adolescents or young adults. ${ }^{6}$ Several strategies working together have been proposed to reduce those rates, ranging from educational programme, ${ }^{42}$ gun control prevention, ${ }^{27}$ the strong rule of law, ${ }^{29}$ and community and state efforts. ${ }^{32} 43$ Homicide is the ultimate form of violence. However, other types of violence affect peoples' lives in many cases with long-lasting consequences. For example, women, children and the elderly bear a higher burden of non-fatal physical, sexual and psychological consequences of abuse. ${ }^{37}$ Moreover, exposure to violence has detrimental consequences over the life course when exposed during early childhood, such as social, emotional and behavioural problems. For example, child maltreatment is a risk factor that increases later involvement in violence in youth, intimate partner violence, homicide prevalence, non-fatal violence-related injuries, among others. Those who experience violence are also more likely to present suicidal and self-harming behaviour. ${ }^{37}$ As a consequence of the high levels of homicides and violence in the region, the health systems of LAC countries will need to be prepared for an increase in mental health issues. Recently, a multisectorial plan of action was planned by WHO to reinforce the role of health systems on addressing violence, particularly in young people and women. ${ }^{37} 45$ The overall mental distress of the population exposed to violence is unquantifiable. ${ }^{46}$ Some LAC countries, such as Mexico and Venezuela, have experienced a marked increase in homicide rates in recent years. ${ }^{4}$ Although for different reasons, with Mexican violence emerging after the "war on drugs ${ }^{1819}$, and Venezuela's high levels related to political conflict, ${ }^{47}$ both have translated in losses of economy, health and ultimately lives. This has happened in the region, despite ongoing interventions. ${ }^{44}{ }^{48}$ Moreover, a great share of LAC countries have integrated national plans that address multiple types of violence. However, for some countries, there were no data from national surveys on interpersonal violence, suggesting that much planning and policy-making is done in the absence of evidence. ${ }^{48}$ Therefore, these efforts do not match the scale of the burden of violence ${ }^{48}$ and further collective initiatives are needed.

Substantial improvements in life expectancy at relatively low costs were achieved in the region in the recent past by gearing efforts towards the provision of health-related public goods (sanitation, vaccination programme, etc).$^{26}$ Given the complexity of reasons for violence in the region, ${ }^{49}$ homicide will require a variety of strategies, among others reducing the high-income inequality prevailing in the region..$^{50}$ The countries in the region have to address this problem together, but at the same time, national solutions are urgently needed. Breaking the epidemiological cycle of violence transmitting violence-where the probability of acting violent is increased by having violence done to you-should be addressed by decision-makers in LAC immediately, and the health of the young generation needs to be given a high priority.

Acknowledgements We would like to thank the editor and three reviewers of BMJ Global Health, Sergi Trias-Llimós, Bernardo Lanza Queiroz and Luis Gabriel Cuervo, for their insightful suggestions and comments which helped improve the message of our manuscript. We thank the generous support of the University Library of Southern Denmark for sponsoring the publication of our study.

Contributors Both authors were actively involved in conceptualising the study. VC-R and JMA conducted the data management and analysis. Both authors were actively engaged in discussing the ongoing progress of the analysis and interpretation of findings. VC-R drafted and revised the manuscript on the basis of comments provided by JMA. Both authors have approved the final version of the manuscript. VC-R is the final guarantor of the study.

Funding This study was funded by World Bank Group (Short term consultancy project).

Competing interests None declared.

Patient and public involvement statement This study involved secondary data analysis of public sources, which did not involve patients nor public (PPI).

\section{Patient consent for publication Not required.}

Ethics approval This study involved secondary data analysis of public sources, which did not have any individual identifiers, therefore ethics approval from our respective Institutional Review Board (IRB) was not required.

Provenance and peer review Not commissioned; externally peer reviewed.

Data sharing statement The full datasets are publicly available online and can also be requested from the corresponding author.

Open access This is an open access article distributed in accordance with the Creative Commons Attribution Non Commercial (CC BY-NC 4.0) license, which permits others to distribute, remix, adapt, build upon this work non-commercially, and license their derivative works on different terms, provided the original work is properly cited, appropriate credit is given, any changes made indicated, and the use is non-commercial. See: http://creativecommons.org/licenses/by-nc/4.0/. 


\section{REFERENCES}

1. Institute of Health Metrics and Evaluation IHME, 2018. Available: http://www.healthdata.org/

2. United Nations. World population prospects, 2017. Available: https:// esa.un.org/unpd/wpp/Download/Standard/Mortality/

3. World Health Organization, WHO. Mortality database, 2018. Available: http://www.who.int/healthinfo/mortality_data/en/

4. United Nations Office on Drugs and Crime, UNODC. Global study on homicide, 2013. Available: https://www.unodc.org/documents/gsh/ pdfs/2014_GLOBAL_HOMICIDE_BOOK_web.pdf

5. United Nations Office on Drugs and Crime, UNODC. Homicides database, 2018. Available: https://data.unodc.org

6. Briceño-León R, Villaveces A, Concha-Eastman A. Understanding the uneven distribution of the incidence of homicide in Latin America. Int J Epidemiol 2008;37:751-7.

7. Roth GA, Johnson C, Abajobir A, et al. Global, regional, and national burden of cardiovascular diseases for 10 causes, 1990 to 2015 . J Am Coll Cardiol 2017;70:1-25.

8. Moran AE, Forouzanfar MH, Roth GA, et al. Temporal trends in ischemic heart disease mortality in 21 world regions, 1980 to 2010: the global burden of disease 2010 study. Circulation 2014;129:1483-92.

9. Christensen K, Doblhammer G, Rau R, et al. Ageing populations: the challenges ahead. The Lancet 2009;374:1196-208.

10. Soares RR. On the determinants of mortality reductions in the developing world. Popul Dev Rev 2007;33:247-87.

11. Roth GA, Forouzanfar MH, Moran AE, et al. Demographic and epidemiologic drivers of global cardiovascular mortality. $N$ Engl $J$ Med 2015;372:1333-41.

12. Kassirer JP. Guns, society, and medicine. N Engl J Med 2015;372:874-5

13. Canudas-Romo V, Aburto JM. Age- and cause-decomposition of the difference in life expectancy in Latin american and Caribbean countries, 2017. Available: https://wb-lac.shinyapps.io/lac_diversity/

14. UN demographic yearbooks. Life tables for all Latin American and Caribbean countries, 2018. Available: http://data.un.org/

15. Economic Commission for Latin America and the Caribbean, CEPAL. Life tables elaborated by CEPAL 2004 and 2010, 2018. Available: https://www.cepal.org/en/datos-y-estadisticas

16. Latin America mortality database, Lambda, 2018. Available: https:// www.ssc.wisc.edu/cdha/latinmortality/

17. Economic Commission for Latin America and the Caribbean. Life tables elaborated by statistical offices in the region, 2018. Available: http://www.cepal.org/es/temas/censos-de-poblacion-yvivienda/enlaces-institutos-nacionales-estadistica-america-latinacaribe

18. Aburto JM, Beltrán-Sánchez H, García-Guerrero VM, et al. Homicides in Mexico reversed life expectancy gains for men and slowed them for women, 2000-10. Health Aff 2016;35:88-95

19. Canudas-Romo V, García-Guerrero VM, Echarri-Cánovas CJ. The stagnation of the Mexican male life expectancy in the first decade of the 21st century: the impact of homicides and diabetes mellitus. $J$ Epidemiol Community Health 2015;69:28-34.

20. SOMEDE, Mexican Demographic Society. Demographic estimates for Mexico and its states, 1990-2010. (in Spanish: Estimaciones demográficas de México Y entidades federativas, 1990-2010). Mexico: National Population Council and SOMEDE, 2011.

21. Jackson $\mathrm{CH}$. Multi-State Models for Panel Data: The msm Package for R. J Stat Softw 2011;38:1-29.

22. The human mortality database, 2018. Available: www.mortality.org

23. Arriaga EE. Measuring and explaining the change in life expectancies. Demography 1984;21:83-96.

24. Preston S, Heuveline P, Guillot M. Demography; measuring and modeling population processes. Oxford: Blackwell Publishers, 2001.

25. Ihaka R, Gentleman R. R: a language for data analysis and graphics. Journal of Computational and Graphical Statistics 1996;5:299-314.

26. Soares RR. Life expectancy and welfare in Latin America and the Caribbean. Health Econ 2009;18(Suppl 1):S37-S54.
27. Patton GC, Coffey C, Sawyer SM, et al. Global patterns of mortality in young people: a systematic analysis of population health data. The Lancet 2009;374:881-92.

28. Bloom DE, Canning D. The health and wealth of nations. Science 2000;287:1207-9.

29. Fraser B. Latin America looks to violence prevention for answers. The Lancet 2012;380:1297-8.

30. Soares RR, Naritomi J. Understanding high crime rates in Latin America: The role of social and policy factors. [In] The economics of crime: Lessons for and from Latin America. University of Chicago Press, 2010.

31. World bank EduStats database. Available: https://data.worldbank. org/topic/education

32. Hoffman JS, Knox LM, Cohen R. Beyond suppression: global perspectives on youth violence. ABC-CLIO 2011.

33. Rivera M. The sources of social violence in Latin America: an empirical analysis of homicide rates, 1980-2010. Journal of Peace Research 2016;53:84-99.

34. Moncada E. Counting bodies: crime mapping, policing and race in Colombia. Ethn Racial Stud 2010;33:696-716.

35. Rivera LG, Gutierrez Rivera L. Discipline and punish? Youth gangs' response to "zero-tolerance" policies in Honduras. Bull Lat Am Res 2010;29:492-504.

36. Menjivar C, Walsh SD, Drysdal Walsh S. The architecture of feminicide: the state, inequalities, and everyday gender violence in Honduras. Lat Am Res Rev 2017;52:221-40.

37. World Health Organization. Global plan of action to strengthen the role of the health system within a national multisectoral response to address interpersonal violence, in particular against women and girls, and against children, 2016. Available: http://apps.who.int/iris/ bitstream/handle/10665/252276/?sequence $=1$

38. Atun R, de Andrade LOM, Almeida G, et al. Health-system reform and universal health coverage in Latin America. The Lancet 2015;385:1230-47.

39. Cecchini S, Veras-Soares F. Conditional cash transfers and health in Latin America. The Lancet 2015;385:e32-4.

40. Etienne C, Abbasi K, Cuervo LG. Research for health in the Americas. BMJ 2018;362.

41. Miranda JJ, Castro-Ávila AC, Salicrup LA. Advancing health through research partnerships in Latin America. BMJ 2018;362.

42. Pinker S. Decline of violence: taming the devil within us. Nature 2011;478:309-11.

43. Wintemute GJ. Guns, fear, the constitution, and the public's health N Engl J Med 2008;358:1421-4.

44. Pan American Health Organization. Adolescent and youth regional strategy and plan of action 2010-2018, 2010. Available: http://iris paho.org/xmlui/handle/123456789/3522

45. World Health Organization. INSPIRE: seven strategies for ending violence against children, 2016. Available: https://www.who.int/ violence injury prevention/violence/inspire/en/

46. Canudas-Romo V, Aburto JM, García-Guerrero VM, et al. Mexico's epidemic of violence and its public health significance on average length of lifEpidemic of Violence and its Public Health Significance on Average Length of Life. J Epidemiol Community Health 2017;71:188-93.

47. Tremaria S. Violent Caracas: understanding violence and homicide in contemporary Venezuela. International Journal of Conflict \& Violence 2016;10:61-76.

48. Pan American Health Organization. Status report on violence prevention in the region of the Americas, 2014, 2016. Available: http://iris.paho.org/xmlui/handle/123456789/18832

49. Briceño-León R. Urban poverty and institutions in Venezuela. In: Salahub JE, Gottsbacher M, De Boer J, eds. Social theories of urban violence in the global South: towards safe and inclusive cities. Abingdon, Oxon; New York, NY: Routledge, 2018: 139-58.

50. Elgar FJ, Aitken N. Income inequality, trust and homicide in 33 countries. Eur J Public Health 2011:21.

51. Krahn H, Hartnagel TF, Gartrell JW. Income inequality and homicide rates: cross-national data and criminological theories. Criminology 1986;24:269-94. 